\title{
Análisis de las estrategias discursivas de los candidatos presidenciales de 2018. Caso de los debates presidenciales y spots televisivos
}

\begin{abstract}
Rosalinda Gámez Gastélum
Profesora-investigadora de la Facultad de Estudios Internacionales y Políticas Públicas de la Universidad Autónoma de Sinaloa. Líder del Cuerpo Académico de Gobierno y Políticas Públicas. Miembro del Sistema Nacional de Investigadores.
\end{abstract}

\section{Resumen:}

El objetivo de este artículo es analizar las estrategias discursivas de los candidatos a la Presidencia de la República en las elecciones de 2018 en México, con el objetivo de identificar los efectos de los mensajes en los potenciales electores. La investigación utiliza metodología cualitativa a partir de un análisis del discurso de los tres candidatos durante los debates presidenciales En ese sentido, se detectó que la palabra más utilizada por Andrés Manuel López Obrador es corrupción; por José Antonio Meade progreso y miedo y por José Antonio Anaya cambio. Respecto a la estrategia de los discursos, se detectó que la más usada es la ad baculum (promoviendo el miedo) en contra de AMLO (por parte de Meade y Anaya), pero que no tuvo efectos importantes en el electorado, debido a que era mayor el hartazgo al régimen político y la corrupción. Por su parte, Andrés Manuel López Obrador la estrategia que más usa es el ad populum, la cual logró buena aceptación.

El trabajo de campo se realizó a partir de un estudio de gabinete de análisis del discurso y en el caso de los spots se utilizaron grupos de enfoques de estudiantes universitarios, para detectar que spots tenían más impacto y por qué (se trabajó con una muestra de 9 spots de los tres principales candidatos). En ese sentido, se encontró que los estudiantes universitarios tienden a identificarse más con el mensaje de Andrés Manuel López Obrador, destacando el spot en donde llama \"marranos y cochinos $\backslash$ " a la mafia del poder (un $85 \%$ ) . En segundo lugar, se identifican con Ricardo Anaya por sus propuestas de cambio y por considerar sus propuestas de política pública innovadora (12\%). En tercer lugar (sólo un $3 \%$ ) se identificó con José Antonio Meade del PRI y menos del 1 \% con \"El Bronco $\backslash "$.

Palabras clave: Análisis del discurso, efectos del mensaje y elecciones.

\begin{abstract}
:
The objective of this article is to analyze the discursive strategies of the presidential candidates in the 2018 elections in Mexico, with the aim of identifying the effects of the messages on potential voters. The research uses qualitative methodology based on an analysis of the speech of the three candidates during the presidential debates. In this sense, it was detected that the word most used by Andrés Manuel LópezObrador is corruption; by José Antonio Meade progress and fear and by José Antonio Anaya change. Regarding the strategy of the speeches, it was detected that the most used is the ad baculum (promoting fear) against AMLO (by Meade and Anaya), but that it did not have important effects on the electorate, because it was greater the satiety of the political regime and corruption. For his part, Andrés Manuel LópezObrador, the strategy he uses the most is ad populum, which achieved good acceptance.
\end{abstract}




\section{DOI: $10.51386 / 25815946 / i j s m s-v 4 i 4 p 126$}

Volume: 4 Issue: 4

July to August 2021

https://www.ijsmsjournal.org

The field work was carried out from a study of discourse analysis office and in the case of the spots, groups of approaches from university students were used, to detect which spots had the most impact and why (we worked with a sample of 9 spots of the three main candidates). In this sense, it was found that university students tend to identify more with AMLO's message, highlighting the spot where he calls the power mafia $\backslash$ "pigs and pigs $\backslash$ " (85\% of the 16 participants in the group of focus). Second, they identify with Ricardo Anaya for his proposals for change and consider his proposals for innovative public policy (12\%). Third (only 3\%) identified with José Antonio Meade of the PRI and less than 1\% with \"El Bronco \".

Keywords: Discourse analysis, message effects and choices.

\section{Introducción}

La llamada mediatización de la política emerge en México a mediados de los noventa con el predominio del uso de los medios masivos de comunicación, la personalización de la política, diseño de discurso basado en los medios, la realización de debates políticos y una utilización masiva de spots políticos. Es decir, acudimos a una nueva etapa, en donde la influencia de las campañas de los Estados Unidos fue fundamental en el diseño de campaña en México y América Latina.

Este artículo analiza como unidad de análisis una muestra de nueve spots, trasmitidos por televisión abierta en el periodo de campaña y considerados como los de mayor rating en las elecciones presidenciales de 2018 en México a partir de las estrategias discursivas utilizadas.El objetivo de esta investigación es conocer cuál es el impacto que tuvieron en el electorado o bien si solo son efectivos sus mensajes en los llamados electores indecisos o flotantes, los cuales en las democracias modernas son quienes inclinan el fiel de la balanza.

Este trabajo tiene como objetivo analizar las estrategias discursivas de los tres principales candidatos en las elecciones federales de 2018 (José Antonio MeadeKuribeña, Andrés Manuel López Obrador y RicardoAnaya Cortez, así como Jaime Rodríguez "El Bronco”).

Estas elecciones son particularmente importantes en comunicación política, debido a que Andrés Manuel López Obrador es la tercera vez que se postula como candidato a la presidencia (participó en 2006 y 2012); por primera vez en más de 80 años de historia, el PRI, postula a un candidato ciudadano (no afiliado a su partido) y también por primera vez se postulan candidatos, bajo la figura de candidato independiente, Jaime Rodríguez y Margarita Zavala).

Si partimos de la premisa, de que la comunicación política puede ser vista como el enfrentamiento de mensajes entre los distintos actores políticos (Cannel, 2004). Es muy relevante efectuar un análisis de los mensajes que intercambiaron los actores políticos, mediante los spots televisivos, como principal herramienta de campaña para llegar al electorado y, en segundo lugar, los debates políticos televisados que representan la americanización plena de las campañas mexicanas, dado que los electores ven a sus candidatos como peleadores que suben a un ring y eso genera un gran interés y expectación.

\section{Estrategias discursivas de campaña.}

El discurso político entraña enfrentamiento y lucha entre enunciadores que, así como en la antigüedad se desplegaban en torneos de oratoria, hoy son reproducidos y dramatizados en la arena de los medios. Los procesos argumentativos en política es diálogo, pero es también un simulacro de combate que se ofrece a un público constituido por audiencias de millones gracias a los medios de comunicación de masas (Dorna, 1993: 118, citado por García, 2005).

Las estrategias discursivas pueden ser definidas como medios para lograr la persuasión. Consisten en prácticas conformadas por secuencias de procedimientos verbales y no verbales, determinadas por un fin u objetivo, que sirve para alcanzar ciertas metas (Montero, 1994).

Todo discurso político de campaña involucra la presencia de tres elementos: Un candidato enunciador, un auditorio o público ante el que se habla y un conjunto de destinatarios o personas a quienes realmente se 


\section{DOI: $\underline{10.51386 / 25815946 / i j s m s-v 4 i 4 p 126}$}

Volume: 4 Issue: 4

July to August 2021

https://www.ijsmsjournal.org

dirige: No siempre auditorios y destinatarios resultan categorías consientes cuando se trata de escenarios proselitistas (García, et al, 2006).

Según Graver (1987), el discurso político de campaña cumple cinco funciones: 1) Crea una realidad favorable para el candidato, 2) reconstruye el pasado y predice el futuro, 3) liga al candidato con símbolos positivos , 4) Fija la agenda de la campaña y 5) estimula el voto. En otras palabras, lo que los candidatos dicen construyen un marco general (frame) para los votantes.

Diversos autores encuentran que las estrategias discursivas desplegadas durante dichas contiendas cumplen importantes funciones. Mangone y Warlet (1994) proponen una tipificación general, conformada por tres amplias categorías, de los fines de las estrategias más empleadas en los discursos del ámbito político, a saber:

- Provocación: Para captar la atención del receptor.

- Apelación: Para involucrar al receptor en el sistema de valores que se defiende.

- Intimidación: Para disuadir al receptor de una opinión distinta.

Los expertos en comunicación política Denton Jr. Y Woodward (1998, citado por Virginia et al 2005) Especifican aún más los fines estratégicos con los que el lenguaje político puede ser utilizado:

- Argumentación y persuasión: Creación de una realidad simbólica para alterar o mantener ciertas actitudes, valores y creencias desde una perspectiva particular y para un propósito específico.

- Identificación: Generación de un sentimiento de unidad.

- Refuerzo: De actitudes y creencias ya existentes acerca de metas y valores a los que se dirige el grupo.

- Inoculación: Estrategia para promover la resistencia al cambio de actitudes, adelantando la presentación de contrargumentación para defender la propia posición.

- Polarización: Reducción de una cuestión que tiene muchas facetas a solo dos lados, ignorando los grises. También: Distinguir y separar gente, cuestiones e ideas.

- Etiquetamiento: De cuestiones, candidatos y políticas. Esto transforma a las campañas en concursos por establecer la definición de la realidad social.

- Expresión: El lenguaje político, a través de símbolos, rituales y palabras, permite la expresión no solo de ideas sino también de esperanzas y temores.

- Dramatización: La mayoría de los eventos políticos son dramáticos y por eso tienen gran importancia las formas dramáticas de comunicación.

\subsection{Tipos de estrategias discursivas usadas en campañas electorales}

A su vez, Montero (1999), identifica trece estrategias discursivas.

- Yuxtaposición creadora de implícitos.

- Generalización y vaguedad.

- Despersonalización del referente.

- Atribución de pasividad y falta de dinamismo al otro.

- Despolitización, o evasión del contenido del conflicto.

- El uso de detalles o descripciones vívidas.

- Dar al discurso una forma narrativa.

- La invocación al principio de autoridad.

- Búsqueda de consenso y corroboración mediante otras autoridades o testimonios de personas que puedan considerarse imparciales.

- Uso de metáforas o hipérboles.

- Ordenar el discurso en listas para crear la ilusión de exhaustividad y de objetividad.

- El silencio o parquedad. 


\section{DOI: $10.51386 / 25815946 / i j s m s-v 4 i 4 p 126$}

Volume: 4 Issue: 4

July to August 2021

https://www.ijsmsjournal.org

- La imagen o el ícono para sustituir a la palabra.

En tanto, Hall Jamineson (1988; citado por Virginia et al 2006) Sostiene que en una época en la que la televisión nos ha acostumbrado a ver argumentos políticos, los discursos deben crear imágenes mediante las palabras, e inclusive, apelar al recuerdo que tenemos de acciones que hemos visto televisadas. Para esta autora, una de las estrategias discursivas más poderosas es la narrativa, e indica que en la actualidad se utilizan cuatro tácticas a su servicio:

- La dramatización.

- El relato de cuentos o historias.

- La conversación.

- La autorrevelación (self-revelation, self-disclosure).

Las dos primeras -la dramatización y el relato de historias - involucran la utilización de ciertos recursos cruciales:

- La puesta en escena en escena y la correcta selección de puntuales sobre los cuales ilustrar los discursos.

- La personificación de ciertos temas a través de narrativas que muestran la vida de ciudadanos comunes:

- La construcción de argumentos sobre una escena visual que la nación haya experimentado recientemente, es decir, empleando a experiencias visuales compartidas por el colectivo de ciudadanos

- La sinopsis y evocación de los sentimientos de la audiencia a través del uso de detalles vívidos.

Cuando se refiere a la tercera de las tácticas enumeradas, la conversación, Hall Jamieson destaca el poder de los discursos que tienen un estilo conversacional en lugar de uno formal o de oratoria clásica: La televisión no le habla a multitudes sino a individuos.

La cuarta táctica enumerada, la autorrevelación, se refiere a la exposición que hace un candidato de facetas de sí mismo o de su pasado personal, no de su trayectoria política.

Diaz Barrado (1989) es otro de los autores que se ha ocupado de tipificar estrategias del discurso político. Identifica un conjunto conformado por siete, que a su criterio todo orador utiliza para reducir el antagonismo que los separa de la audiencia derivado de la posición de poder asimétricaque ocupa respecto a ella:

- Sublimación .

- Favor.

- Desviación.

- Miedo.

- Culpabilidad.

- Represión.

- Expulsión.

\subsubsection{Técnicas de propaganda y discurso político}

La literatura en comunicación política documenta una nutrida serie de técnicas de propaganda que, pueden ser también utilizadas y consideradas a modo de estrategias discursivas. Serie el caso, por ejemplo, del uso de insultos para atacar a un oponente (name-calling), definido como adjudicar una etiqueta negativa sin considerar la evidencia que los sustenta. Por ejemplo: en la elección que se analiza el candidato Andrés Manuel López Obrador pone la etiqueta de mafia del poder a candidatos del PRI, PAN, incluso a la independiente Margarita Zavala. 


\section{DOI: $10.51386 / 25815946 / i j s m s-v 4 i 4 p 126$}

Volume: 4 Issue: 4

July to August 2021

https://www.ijsmsjournal.org

Asimismo, la transferencia positiva, entendida como el traspaso de la autoridad o del prestigio de una idea, objeto o persona a otra. Esta estrategia se hizo evidente en cada oportunidad en la que Menem se compraba con el General Perón (García, et al 2005).

Otras posibilidades discursivas que derivamos del mismo grupo de técnicas de propaganda son:

- Uso de testimoniales positivos.

- Volver algo deseable por asociación.

- Culpabilidad por asociación.

- Uso de pruebas estadísticas.

- Sobregeneralización.

- Falsas analogías.

- Apelaciones tautológicas.

- Falacia de las alternativas limitadas.

- Falacia de la imposible certeza.

- Construcción de significado y credibilidad a través de fuentes secretas.

- Referirse a gente común, asociando las ideas del orador con personas, modos costumbres o el lenguaje de la gente común e insinuando que por tanto estos ítems son, por tanto, superiores.

- Argumentos del tipo llamamiento a unirse a los triunfadores (Bandwagon appeal).

- Apelaciones de superioridad.

- Los hombres sabios no pueden equivocarse.

- Apelaciones de miedo prospectivas.

- Apelaciones de miedo retrospectivas.

- Apelaciones al absurdo.

- Discurso del odio.

- Ataques personales.

- Utilización de la identificación cartica (Virginia, et al, 2006). 1.2 El rol de los spots en campañas políticas

Los spots televisivos tienen una gran importancia en las campañas políticas, ya que se ha encontrado una relación positiva entre los resultados electorales y los gastos de publicidad televisiva que realizan los candidatos. Además de que los anuncios televisivos tienen gran efecto en el electorado para recordar al candidato, influir en su intención de voto o actitudes hacia el candidato.

\section{Clasificación de los spots políticostelevisivos}

A. Anuncios positivos, los cuales son los que se enfocan principalmente en las cualidades de los candidatos.

B. Anuncios de contraste, que son los que realizan comparaciones explícitas con respecto a su adversario

C. Anuncios negativos, que resaltan las deficiencias o debilidades del oponente (García, D’Adamo y Slavinsky, 2006). Los autores resaltan que es más habitual el diseño de anuncios de comparación que la publicidad de ataque.

Se plantea una clasificación de dos tipos de comerciales de contraste: aquellos que son de contraste directo, en los cuales se puede observar la comparativa de un candidato, su tema o su posición con respecto a la de su adversario y los comerciales políticos televisivos de contraste implícito, en los que se permite al elector realizar sus propias deducciones e inferir sobre las críticas al candidato de oposición (Johnson-Cartee y Copeland, 1997ª citado por Maldonado, 2013). 


\section{DOI: $10.51386 / 25815946 / i j s m s-v 4 i 4 p 126$}

Volume: 4 Issue: 4

July to August 2021

https://www.ijsmsjournal.org

Los spots televisivos negativos se han categorizado en: spots de ataque directo, los cuales se enfocan en las debilidades del oponente. Los anuncios políticos televisivos de comparación directa, donde de una manera competitiva cotejan al autor con su oponente. Y los spots de comparación implícita, que son los que se fundamentan en la interpretación que el elector realiza de ellos (Johnson-Cartee y Copeland, 1991,1997a citado por Maldonado, 2013).

Cabe destacar que de acuerdo a los estudios teóricos, los spots políticos en los que tienen mayor impacto son en los electores indecisos o flotantes (Maldonado, 2013) que en México representan de un 10 a un $15 \%$ del padrón electoral (INE, 2017).

A continuación, se muestran las caras de los candidatos a presidencia de México, en la cual nos brinda el porcentaje de participación por parte de los votantes.

Figura 1. Resultado de porcentaje de votos por candidato presidencial

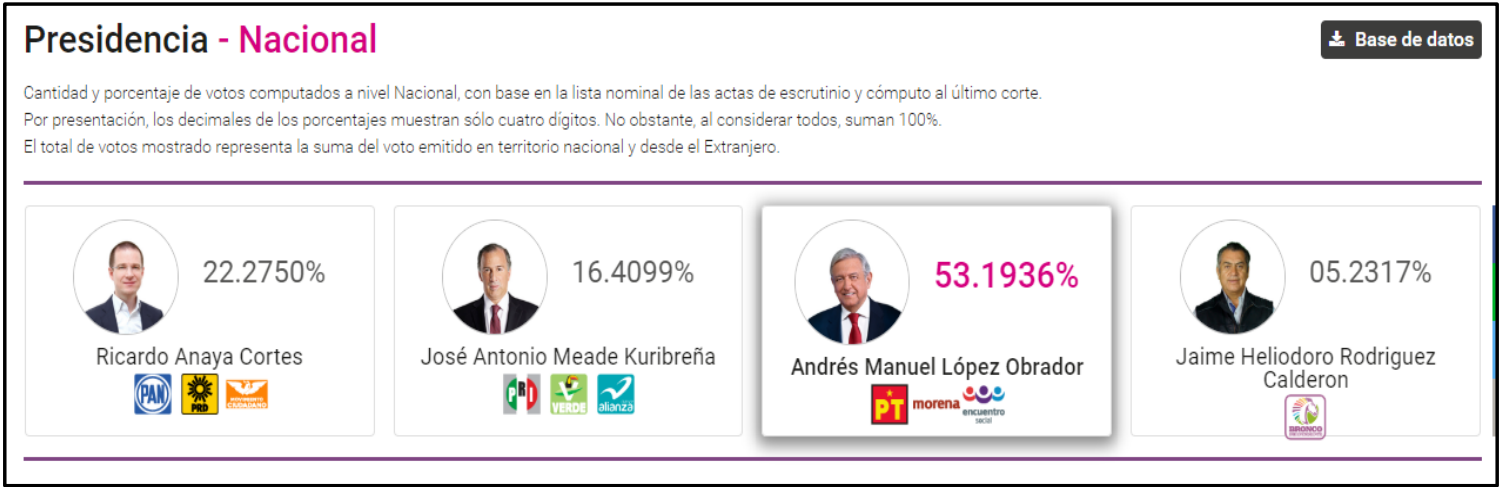

Fuente: Instituto Nacional Electoral (INE, 2018).

Ahora bien, esta investigación de corte cualitativo tiene como guía las siguientes preguntas: : ¿Cuáles fueron las principales estrategias discursivas de cada candidato? ¿En que medida los spots televisivos tienen impacto en el electorado jóven?

Esta ponencia también busca reflexionar sí en la elección de 2018 en México hubo otros actores políticos que con su discurso trataron de influir en el voto, por ejemplo: sector empresarial, organizaciones de la sociedad civil, líderes de opinión pública, representantes de medios de comunicación, etc.

Cabe destacar que detrás de una posición aparentemente apolítica de ciertos grupos civiles seesconden intereses ocultos como alcanzar poder político por otros medios norepresentativos desde discursos antiinstitucionales, populistas, antipartistas,carismáticos. Con este tipo de discursos políticos un candidato puede movilizarfuerzas de la sociedad civil(Aguilera, 2010; citado por Gámez y Hernández, 2018).

\subsection{Metodología}

En esta ponencia se analiza una muestra de nueve spots transmitidos por televisión abierta en la fase de campaña de los candidatos a la Presidencia de la República, de la coalición "Juntos haremos Historia", Andrés Manuel López Obrador; "por México al frente", Ricardo Anaya Cortes y del candidato de "todos por México", José Antonio MeadeKuribeña por televisión nacional en el periodo del 30 de marzo al 27 de mayo de 2018. Se utiliza la técnica de grupos de enfoque (focusgroup) con estudiantes universitarios de 19 a 22 años, con el propósito de analizar si los spots tuvieron algún impacto en el electorado. Se analizan dos grupos de estudiantes universitarios, con características similares. 
DOI: $\underline{10.51386 / 25815946 / i j s m s-v 4 i 4 p 126}$

Volume: 4 Issue: 4

July to August 2021

https://www.ijsmsjournal.org

En ese sentido, la unidad de análisis son los nueve spots analizados a partir de un cuestionario estructurado cerrado, para conocer la impresión de los electores (estudiantes universitarios) sobre el discurso de los candidatos. En el caso de los debates, se analizaron a partir de la teoría de la argumentación (Cappalpi, 2000) y teoría del discurso respecto a aclamación, ataque y defensa (precisar autor).

También se analizan las estrategias discursivas usadas por los candidatos en los tres debates presidenciales de la campaña, organizados por el INE, a partir de revisar las estrategias discursivas para ganarse el beneplácito del público (Cappaldi, 2000), así como apelar a las emociones y la razón de la audiencia. En ese sentido, se realizó la versión estenográfica del debate y posteriormente se realizó un análisis de contenido, para detectar cuáles son las palabras que repitió más cada candidato y que tipo de connotación le dio en su mensaje televisado.

\subsubsection{Impacto de los spots de los candidatos a la presidencia}

De la muestra de nueve spots que se tomaron por considerarlos emblemáticos destaca la propuesta de la coalición por "México al Frente" (Anaya), cuyo proyecto es una apuesta por el futuro; en tanto, Morena y el PRI enfocan su discurso en afirmar que combatirán la corrupción. Ambos partidos dicen el qué, pero no dicen cómo.

\subsubsection{Análisis del discurso de spots de Ricardo Anaya.}

Entre los spots de mayor elocuencia verbal, resalta el del candidato de México al Frente, Ricardo Anaya, quien dice:

"El PRI perderá y los mexicanos tendrán que optar por dos opciones de cambio. En el spot de 30 segundos señala (en una toma de médium shot) "De que México tiene que cambiar no hay duda. El PRI ya se va. La pregunta es: ¿qué tipo de cambio quieres? ¿el de Andrés Manuel? A mí me parece una visión ya anticuada de México y del mundo ¿o el del frente?

El spot cierra con el eslogan de campaña de Anaya "De frente al futuro, Anaya presidente", con lo cual apela a la estrategia discursiva de la esperanza de un mejor futuro para el país y los ciudadanos(Cappaldi, 2000 ).

En el segundo spot analizado de Ricardo Anaya, es un comercial político testimonial, en donde aparecen diferentes figuras emblemáticas de la política mexicana, tales como Luis Donaldo Colosio Murrieta (hijo del candidato inmolado del PRI, Luis Donaldo Colosio); Xochitl Gálvez, senadora panista, Diego Fernández de Cevallos, excandidato presidencial y Gilberto Alfaro, Gobernador de Jalisco, quienes coinciden en afirmar que con Anaya está garantizado el futuro. En ese spot la palabra clave es "futuro" con una connotación positiva respecto al avance de México. Aquí la estrategia discursiva es la testimonial y como el prestigio se transfiere de estos connotados políticos mexicanos al candidato Anaya.

El tercer spot seleccionado por tener el mayor rating de audiencia durante la campaña y su transmisión en señal abierta es el spot, en donde aparece Anaya, junto con un niño huichol, tocando un instrumento musical y donde se caracteriza por tomas abiertas (un paneo de la sierra nayarita) y de fondo el jingle "Movimiento Naranja, Movimiento Naranja, el futuro está en tus manos"con una excelente banda sonora. Este spot en términos de estrategia discursiva busca transmitir la idea de que los mexicanos podemos cambiar nuestro futuro y al presentar un niño, incluso de una etnia huichol, está idea nos evoca a que el mejor futuro será incluyente para todos los mexicanos.

En resumen, las palabras clave de los spots de Ricardo Anaya son: cambio, futuro y acusar a Morena de ser un partido que busca el atraso (esto último lo hace en forma implícita al mostrar imágenes yuxtapuestas). 
DOI: $\underline{10.51386 / 25815946 / i j s m s-v 4 i 4 p 126}$

Volume: 4 Issue: 4

July to August 2021

https://www.ijsmsjournal.org

\subsubsection{Análisis del discurso de los spots de José Antonio Meade.}

A su vez, José Antonio Meade de la coalición "Todos por México", usa el eslogan "Avanzar contigo unidos", lo cual constituye un llamado a los electores a sumarse a su campaña, sintiéndose parte de la misma, lo cual significa una estrategia de marketing emocional.

Del tema de combatir la corrupción encontramos los siguientes comerciales políticos:

"Qué gobierno quiero? Uno que este encabezado por gente decente. Yo he combatido la corrupción toda mi vida. Por mi trabajo hoy muchos políticos están en la cárcel. Tú sabes quienes son”.

"Nunca he vivido por arriba de mis ingresos. Se puede ser servidor público sin lavar dinero, sin tener ranchos, sin vivir con excesos. Yo te ofrezco un gobierno que combata con toda la corrupción”, afirma Meade y al final aparece el logotipo de los tres triángulos de la campaña, en donde la marca PRI casi desaparece. En ese caso, la estrategia discursiva que utiliza es apelar al prestigio como servidor público.

Otro de los spots destacables por resumir su propuesta de política social es:

"Con el programa Avanzar contigo, tus pones las ganas y nosotros el apoyo. Soy José Antonio Meade y voy a avanzar contigo"

Con este spot el candidato busca apelar a la esperanza de los ciudadanos de un mejor futuro, así como busca llegar al target de los más de 55 millones de mexicanos en situación de pobreza o que viven por debajo de la línea de bienestar (Coneval, 2017).

En un tercer spot, analizado en el focusgroup, el candidato Meade aparece de espaldas en primer cuadro, en donde aparece una Televisión blanco y negro (antigua encendida), en donde se escucha una voz en off que dice:

"Vamos acabar con los 55 millones de pobres en México"

El candidato apaga el televisor y expresa "Nombre son unos genios", en tono irónico y luego expresa que él como titular de la Secretaría de Desarrollo Social sacó a 2 millones de mexicanos de la pobreza y enseguida pide el voto a su favor por tener experiencia. Aquí la estrategia discursiva es apelar a su conocimiento y hacer referencia implícita a la campaña de Andrés Manuel López Obrador, quien tiene el lema "Primero los Pobres" y promete acabar con la pobreza de llegar al Gobierno Federal.

\subsubsection{Análisis del discurso en los spots de Andrés Manuel López Obrador}

En tanto, el candidato de la coalición "Juntos haremos historia", Andrés Manuel López Obrador su mensaje central es el combate a la corrupción, que no asusten a los ciudadanos con posibles catástrofes si llegan al poder, así como la promesa de austeridad económica en el gobierno y poner fin a los gasolinazos. Afirma que la gente no debe tener miedo que llegue al poder y pide a los electores que lo ayuden a tener mayoría en el Congreso, votando por los candidatos a diputados y senadores de Movimiento de Regeneración Nacional (MORENA).

El elemento central de su discurso es la promesa de combate frontal a la corrupción y sacar a la mafia del poder del Gobierno; sin embargo, tampoco dice el cómo y la totalidad de los spots analizados se enfocan en capitalizar el descontento social. Este es uno de los spots más publicitado en la primera fase de la campaña:

"La gente no debe tener miedo de que llegue al gobierno. No los defraudaré", repite de manera categórica.

"Los que quieren el cambio, porque no quieren dejar de robar; pretenden asustar diciendo que si ganamos México va a ser como Venezuela. Nosotros nos inspiramos en lo mejor de nuestra historia nacional. Ni chavismo, ni trumpismo. Sí juarismo, maderismo, cardenismo y mexicanismo. Que no te asusten, ten confianza. Yo no te voy a fallar", expresa LópezObrador en una toma abierta, en un espacio abierto, que asemeja un parque público, cuyo fondo verde transmite tranquilidad y esperanza en términos de comunicación 


\section{DOI: $10.51386 / 25815946 / i j s m s-v 4 i 4 p 126$}

Volume: 4 Issue: 4

July to August 2021

https://www.ijsmsjournal.org

no verbal. En ese spot su estrategia es la sublimación, pues hace referencia a la historia de México y valores compartidos con Bénito Juárez, Francisco I Madero, así como al general Lázaro Cárdenas.

Otro de sus spots emblemáticos, es el transmitido por el Partido Encuentro Social (PES), participante también en la coalición, el cual señala lo siguiente:

"Los gobernantes y los traficantes de influencias en nuestro país se roban 500 mil millones de pesos cada año. Son niños de pecho estos que presentan como grandes delincuentes en comparación de los políticos corruptos del país. Vamos a terminar con el blindaje oficial".

En este último comercial político aparece vestido de traje y con movimiento de manos enfatiza sus palabras.

Usa como palabras clave: combate a la corrupción, la mafia del poder y la esperanza de México. En ese sentido es un argumento ad populum, en donde difícilmente se podría estar en desacuerdo con su planteamiento, pues toda la audiencia comparte la necesidad de combatir la corrupción.

Durante el focusgroup, los estudiantes universitarios manifestaron estar más influenciados por el mensaje del candidato de la coalición "Juntos Haremos Historia”, Andrés Manuel López Obrador (un $85 \%$ de la muestra), un $16 \%$ se identificó con la estrategia discursiva de Anaya; $3 \%$ con José Antonio Meade y un $1 \%$ con el candidato independiente "El Bronco".

\subsection{Análisis de spots de otros actores políticos}

\subsubsection{Interpretación de campaña del miedo, lanzada por el PRI}

A 50 días de las elecciones, la mayoría de las casas encuestadoras ubicaron a Andrés Manuel López Obrador como el puntero de las encuestas con $44 \%$; Ricardo Anaya del PAN-PRD-MC con $31 \%$; José Antonio Meade del PRI-PVEM y PANAL con un lejano $17 \%$. En tanto Margarita Zavala con una intención de voto del $5 \%$ y El Bronco con $3 \%$. Tras el primer debate, los números se movieron solo un punto porcentual (Reforma, mayo 2018).

Esta situación genero un gran desespero en el cuarto de guerra de la campaña del candidato a la Presidencia, José Antonio Meade, quien relanzó su campaña con el eslogan "Avanzar contigo" y realiza una serie de promesas en materia de política social. Sin embargo, el relanzamiento lejos de posicionarlo lo ha consolidado en el penoso tercer lugar de la intención de voto de la ciudadanía. Es tal la exasperación del PRI, que ha divulgado en redes sociales, que están en segundo lugar de las encuestas, incluso la estructura priista salió a las calles con toda su estructura gubernamental.

Sin embargo, difícilmente remonto de esa posición, ya que entre la población existe un hartazgo por la situación económica del país, el precio galopante de la gasolina, la inseguridad que cada día va en aumento y la pésima administración del Presidente, Enrique Peña Nieto.

\subsubsection{2 ¿Miedo o Meade?}

La intensa campaña que ese partido lleva a cabo en los medios masivos de comunicación, no ha logrado impactar ni a los indecisos. Los estrategas en comunicación política del PRI han llegado al extremo de crear una campaña en spots de televisión y redes, en donde ponen al electorado en la disyuntiva de Miedo o Meade. Esa estrategia se denomina en argumentación ad baculum(Capaldi, 2000)y consiste en generar una campaña de terror entre la población, para que reaccione de manera instintiva y vote por el PRI. En la anterior campaña dio un buen resultado, cuando la COPARMEX se subió a la arena electoral y posiciono la idea de que López Obrador era un peligro, para México.

Actualmente, esa estrategia ya no funciona más en México. Es mayor el hartazgo contra la inseguridad, la corrupción y los males gobernantes que cualquier miedo que quieran infundir. La realidad supera cualquier ficción, pues 55 millones de pobres en México confirman que peor no se puede estar (Coneval, 2017). 


\section{DOI: $10.51386 / 25815946 / i j s m s-v 4 i 4 p 126$}

Volume: 4 Issue: 4

July to August 2021

https://www.ijsmsjournal.org

Cabe mencionar que de nuevo el sector empresarial, trato de influir en la opinión pública a través de la asociación "Mexicanos Primero", impulsora de la reforma educativa, con un spot (aparentemente inocente, pero no era tal) de unos niños que personificaban a los candidatos a la presidencia y pedían que continuará la reforma educativa y se apoyará al candidato que estuviera a favor de ésta. Afortunadamente, el Tribunal Electoral dictaminó que ese anuncio debe ser retirado, a petición de MORENA que se quejó ante el órgano electoral.

En el siguiente aparatado, se analizan las principales propuestas de campaña, presentadas en los tres debates presidenciales a partir de una metodología cualitativa de narrativa y análisis de la estrategia discursiva de los candidatos en los temas centrales de la campaña.

\subsection{Debates presidenciales}

El debate representa una confrontación de ideas entre los contendientes a diferentes puestos de elección popular. Esta estrategia electoral surge en los Estados Unidos desde la década de los ochenta y alcanza su mayor auge en las campañas presidenciales de Ronald Reagan y Bill Clinton en la década de los ochenta y noventa (Gámez, 1999).

\subsubsection{Primer debate presidencial}

Interesante y controversial el debate entre los candidatos a la presidencia, en donde se advirtió el interés de todos por desbarrancar al candidato de la coalición "Juntos haremos historia", Andrés Manuel López Obrador; sin embargo, éste se replegó en sí mismo y evadió los cuestionamientos y los ataques como una estrategia, para evitar confrontarse. Su estrategia discursiva fue la desviasión.

Si partimos del análisis de la estrategia argumentativa, el candidato que tuvo mejor desempeño en el debate fue Ricardo Anaya Cortes, candidato de la coalición "México al frente", quien mostró buena capacidad para comunicar sus propuestas, cuestionar a José Antonio Meade del PRI y a Andrés Manuel López Obrador. Su estrategia fue el ataque.

Anaya hizo uso de recursos no verbales, tales como gráficas, fotografías, incluso mando diseñar un sitio de internet especial para evidenciar las propuestas de López Obrador. Respecto a las acusaciones en su contra por presunta corrupción, se defendió mostrando un documento, en donde acusó a la PGR de actuar en forma facciosa en su contra.

Por su parte, la candidata independiente, Margarita Zavala se dirigió al segmento de las mujeres como electoras y en ellas centro su mensaje, orientado a rescatar los valores y la familia. Zavala recibió fuertes ataques respecto a la administración de su esposo, el ex presidente Felipe Calderón Hinojosa, pero se deslindó aclarando que tiene identidad propia y que su gobierno no será una reelección al de Felipe Calderón.

En tanto, Jaime Rodríguez "El Bronco" con el uso de un lenguaje coloquial, se enfocó a criticar principalmente a Andrés Manuel López Obrador, a quien cuestionó seriamente su honestidad y sí estaría dispuesto a regresar el dinero público de la campaña; a lo cual López Obrador respondió que es mil veces honesto. La estrategia de Rodríguez fue el ataque.

El candidato del PRI, José Antonio Meaderepitiólo mismo que en sus spots: que es honesto, tiene capacidad para gobernar y es un candidato ciudadano En una parte de su discurso, afirmó que es el único candidato honesto que ha postulado el PRI en su historia a la presidencia, entonces la gran pregunta sería ¿sus antecesores fueron deshonestos? Respecto a estrategias de presentación de argumentos, Andrés Manuel López Obrador y José Antonio Meade en sus discursos buscaron subirse "al carro de la victoria", principalmente el primero que mostró las encuestas que lo ponen muy por encima de sus adversarios políticos. Esa estrategia consiste en hacer creer al público de que lleva la victoria electoral; por lo que todos los ciudadanos indecisos deberán sumarse a su campaña si no desean quedar como perdedores. 
DOI: $\underline{10.51386 / 25815946 / i j s m s-v 4 i 4 p 126}$

Volume: 4 Issue: 4

July to August 2021

https://www.ijsmsjournal.org

Otra estrategia observada fue la que utilizo Jaime Rodríguez "El Bronco", quien apelo a la compasión al inicio del debate al mostrar una bala, con la cual según dijo, le habían matado un hijo. Sin embargo, su estrategia de compasión no hizo gran eco en la audiencia.

Apelar a la compasión, generalmente funciona muy bien, sobre todo en un país donde hay millones de muertos y miles de desaparecidos a causa de la violencia. Sin embargo, Jaime Rodríguez se perdió en su argumentación en el resto del debate y su discurso estuvo basado en sofismos y falacias.

En resumen, los candidatos se dedicaron, la mayor parte del tiempo, a repartir ataques y a defenderse, mientras que sus propuestas en seguridad, justicia, combate a la corrupción y apoyo a grupos vulnerables fueron bastante inacabadas.

\subsubsection{Segundo debate presidencial}

Realizado en Tijuana, Baja California el pasado 20 de mayo de 2018, con nuevo formato de ciudadanos como participantes con preguntas clave sobre política exterior, la vida en la frontera, apoyo a migrantes centroamericanos, derechos humanos y México en el ámbito global.

El segundo debate presidencial, rumbo a las elecciones 2018, no respondió a las elevadas expectativas que se tenían sobre la visión de los presidenciables de México hacia el mundo. La mayoría de los candidatos exhibió su ignorancia sobre temas internacionales, pero quien manejo más falacias fue Jaime Rodríguez, "El Bronco". Totalmente relajado, utilizó su espacio en ocurrencias y lo más decente que dijo fue que ampliaría el acuerdo comercial a Asia (China y Japón). Se dedicó a provocar al candidato de "Juntos Haremos Historia", Andrés Manuel López Obrador, quien finalmente acabó dando saludos y abrazos a sus adversarios políticos, particularmente a Ricardo Anaya, candidato de "México al Frente", quien durante 13 ocasiones atacó verbalmente a AMLO y a Meade.

Ricardo Anaya Cortes, candidato de "México al Frente" fue quien más polemizo y llego mejor armado al debate, pero cayó en algunas falacias al acusar a sus adversarios políticos, tales como que en la administración de AMLO en la ciudad de México cayó la Inversión Extranjera Directa. También destacó que el consumo de la mariguana era legal en todo el polo norte, lo cual es inexacto.

A su vez, José Antonio Meade centró su estrategia discursiva en presentar sus propuestas de campaña y no respondió en forma puntual, lo que el público le cuestionaba. Por momentos era aburrido y parecía un maestro de secundaria, dando clases. La gran crítica para José Antonio Meade, fue su actuar como canciller.

Respecto a estrategias no verbales, quien la empleó adecuadamente fue Andrés Manuel López Obrador. El candidato escondió su cartera, ante la cercanía de Ricardo Anaya, con lo cual de manera implícita le dijo ratero. Al guardarse la cartera, cada vez que se le acercaba Anaya y expresar "Anaya, Ricky, riquin,Canayin". Esta estrategia fue un agente distractor y atribuyó en forma explícita el antivalor de ladrón a Anaya.

\subsubsection{Tercer debate presidencial}

El tercer debate presidencial se llevó a cabo en Mérida, Yucatán con la asistencia de Andrés Manuel López Obrador (Juntos haremos historia), Ricardo Anaya Cortes (Por México al frente), José Antonio MeadeKuribeña (todos por México) y el candidato independiente, Jaime Rodríguez "El Bronco". En este tercer debate, la gran ausente fue la candidata independiente, Margarita Zavala, quien renunció a su candidatura días antes del debate, bajo el argumento de que lo hacía por ética política y para dejar en libertad a sus seguidores. Lo cierto es que las encuestas la ubicaban apenas con el $3 \%$ de la intención de voto del electorado.

El tercer debate presidencial se caracterizó por los ataques del candidato de "México al Frente", Ricardo Anaya Cortes a Andrés Manuel López Obrador, candidato de la coalición "Juntos Haremos Historia", pero éstos no hicieron mella en el puntero de las encuestas, quien prácticamente "nado de muertito" la segunda 


\section{DOI: $10.51386 / 25815946 / i j s m s-v 4 i 4 p 126$}

Volume: 4 Issue: 4

July to August 2021

https://www.ijsmsjournal.org

parte del debate, en donde su respuesta a todas las grandes interrogantes son el combate a la corrupción y a la mafia del poder (mencione 25 ocasiones esas dos palabras).

El formato del debate parecía un traje a la medida, para el candidato del PRI-Verde y Nueva Alianza, José Antonio Meade, ya que por su expertise como Secretario de Estado en diferentes rubros durante 12 años podría argumentar mejor su propuesta, pero pasó "sin pena ni gloria". Su estrategia de "Avanzar Contigo" en política social fue lo más rescatable. El resto queda para el anecdotario político, tales como "desearle suerte a la selección" a sus adversarios políticos.

\subsection{Estrategia discursiva de agente distractor}

También fue célebre su frase "mejor bésense" cuando discutían Andrés Manuel López Obrador y José Antonio Meade respecto al modelo económico. "El Bronco" dio la impresión de actuar sólo como agente distractor, pero no dio respuesta a las grandes interrogantes de los mexicanos en Desarrollo Económico, Pobreza, Educación, Ciencia y Tecnología, así como salud.

En ese ámbito se identificaron 59 propuestas de los candidatos presidenciales y 36 ataques en un formato de debate, que no permitía mucho la interacción entre los contendientes y más bien presentaba un formato de entrevista con los periodistas, quienes actuaron bien en su papel de moderadores.

\section{Conclusiones}

En esta ponencia pudimos advertir durante el trabajo de gabinete de análisis de los spots y la realización de los grupos de enfoque de jóvenes universitarios en Culiacán, Sinaloa, México que este segmento del electorado tenía una mayor identificación con el candidato Andrés Manuel López Obrador, no obstante ser una persona de la tercera edad, dado que sus estrategias discursivas se enfocaban a desafiar el sistema político y establecía la posibilidad de avanzar hacia una cuarta transformación. Los disparadores de su discurso, que tuvieron mayor influencia en los votantes fue responsabilizar a la mafia del poder de la crisis de pobreza e inseguridad en México. Jugar con la metáfora de la esperanza y comprometerse a combatir la corrupción, mediante un gobierno austero y de búsqueda de equidad entre los mexicanos. Respecto a Ricardo Anaya, quienes se identificaron con él y le dieron su voto fue por su estrategia anclada en el futuro y de construir un mejor país de avanzada. En tanto, las tres personas que dijeron que votaron por José Antonio Meade señalaron que dieron un voto razonado por que prometía implementar la política social "Avanzar Contigo"y la joven que emitió su voto por "El Bronco" explicó que la impresionó su estrategia discursiva de "mocharle la mano a los rateros".

\section{Referencias bibliográficas:}

[1] Aguilera, R. 2010. Educación ciudadana para una cultura de la legalidad. Centro de Altos Estudios e investigación pedagógicas (CAEIP), Consejo Estatal de Ciencia y Tecnología del Estado de Nuevo León, (CECYTE), Gobierno del Estado de Nuevo León, México.

[2] Arendt, H. (2015). Crisis de la República. El cuenco de plata. Buenos Aires.

[3] Ciudadanía política: Voz y participación ciudadana en América Latina 2014: $1^{\text {a }}$ Ed.- Buenos Aires: Siglo Veintiuno Editores,

[4] Cappaldi, N. (2000), Como ganar una discusión, 2da. Reimpresión., Barcelona, España:.Gedisa.

[5] García B. V. et al (2005). Comunicación política y campañas electorales. Estrategias en elecciones presidenciales. España. Gedisa.

[6] García B. V. Adamo D. O. (2006). Comunicación política y campañas electorales: Análisis de una herramienta comunicacional: el spot televisivo. Recuperado de: http://www.scielo.org.mx/pdf/polis/v2n2/1870-2333-polis-2-02-81.pdf. Fecha de consulta 20 de febrero de 2020.

[7] Gámez, R. 1999: Influencia de la televisión en campañas políticas presidenciales en los Estados Unidos. Casos de Reagan y Clinton (1980-1992). Tesis inédita para obtener el grado de Maestra en Estudios de Estados Unidos y Canadá en la UAS, Culiacán, Sinaloa, México. 
DOI: $10.51386 / 25815946 /$ ijsms-v4i4p126

Volume: 4 Issue: 4

July to August 2021

https://www.ijsmsjournal.org

[8] Gámez G. R. y Hernández G. A. 2018: Análisis de promesas de campaña versus realidad: ponencia presentada en el VIII Congreso de la Asociación Mexicana de Ciencia Política (AMECIP) en Puebla.

[9] Maldonado M. L. 2013: Efecto de los spots políticos en la intención del voto. Análisis del papel de los encuadres y las funciones discursivas: Tesis inédita para obtener el grado de doctor en Filosofía con acentuación en Ciencia Política: Universidad Autónoma de Nuevo León: Recuperado de: http://eprints.uanl.mx/3550/1/1080256831.pdf. Fecha de consulta 20 de febrero de 2020.

[10] Monterroso, N., Guadarrama, L. y Zizumbo, L. 2014. Democracia y desarrollo en América Latina. Universidad Autónoma del Estado de México, México

[11] Sitios electrónicos consultados www.animal político.com/2018/04/factibilidad-promesas-candidatos-presidenciales. recuperado el 10 de julio de 2018 .

[12] www.animalpolitico.com/2018/03/candidatos-spots-elecciones/. Recuperado el 11 de julio de 2018.

[13] Periódico Reforma www.Reforma.com, Recuperado el 09 de julio de 2018

[14] Sitio oficial de Instituto Nacional Electoral www.ine.org.mx , Recuperado el 20 de julio de 2018. 